\title{
Models of improved multilink reverse charging network by utilizing the bit error rate QoS attribute
}

\author{
Fitri Maya Puspita ${ }^{1}$, Rohania $^{2}$, Evi Yuliza ${ }^{3}$, Wenny Herlina ${ }^{4}$, Yunita $^{5}$ \\ ${ }^{1,2,3}$ Department of Mathematics, Faculty of Mathematics and Natural Sciences, Sriwijaya University \\ ${ }^{4}$ Department of Mining, Faculty of Engineering, Sriwijaya University \\ ${ }^{5}$ Department of Informatics, Faculty of Computer Science, Sriwijaya University
}

\begin{tabular}{l} 
Article Info \\
\hline Article history: \\
Received Mar 9, 2020 \\
Revised Dec 9, 2020 \\
Accepted Jan 11, 2021
\end{tabular}

\section{Keywords:}

Base price Improved reverse charging Multilink Qos attribute Quality premium The pricing schame

\begin{abstract}
In this paper, a modification model for single-link reverse charging of internet is formed on a multi-link wireless network. The pricing scheme also takes into account the base costs and quality of services provided by the service provider. Bit error rate (BER) was utilized as one of the well-known quality of service (QoS) attribute that can guarantee best performance for internet service provider (ISP) and users. The base price is determined as a decision variable to help ISP to maximize profit. This optimization model can be solved using the LINGO 13.0 program to gain optimal values. The computational results show that by setting costs as constants and service quality as variables, optimal results are obtained for ISPs. This can make ISP considerations in determining the base price that can benefit the ISP and according to the services provided.
\end{abstract}

This is an open access article under the CC BY-SA license.

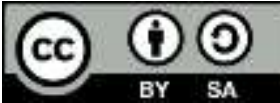

\section{Corresponding Author:}

Fitri Maya Puspita

Department of Mathematics, Faculty of Mathematics and Natural Sciences

Sriwijaya University

Jln. Raya Palembang-Prabumulih, KM 32 Inderalaya Ogan Ilir 30662 South Sumatera, Indonesia

Email: pipitmac140201@gmail.com

\section{INTRODUCTION}

The internet in this modern era is advancing so that the number of internet users every day is always increasing. This condition can be utilized to maximize profits for ISPs $[1,2]$ by also taking into account the level of customer satisfaction. The increasing number of internet users, the demand for quality is also greater. It is a major task for ISPs to provide better and different QoS [3,4] to users in achieving the best quality information at an efficient cost.

Some research $[5,6]$ examined that three internet pricing schemes such as flat rate, usage based, and two-part tariffs in obtaining the profit of ISPs. If dealing with wireless internet pricing scheme then QoS attributes are introduced namely bandwidth, BER, and end to end delay [7, 8]. QoS attribute will be one parameter that is critical in determining the level of quality of network. Base cost which is the cost that is predetermined by ISP to avoid the loss and quality premium which measures the level of quality offered [9], [10] , will also be other parameters that can measure the profit of ISP gains.

One pricing scheme that deals with charging [11] back to user whoever utilize the other network is called reverse charging scheme [12, 13]. Reverse charging is applied for electrical devices [14-16], even vehicles [17, 18] and can be formulates as probabilistic mathematical modelling [19]. Currently, the extensive use of wireless network make ISP attempts to set up new pricing plan based on reverse charging (internet reverse charing-IRC) scheme in wired and wireless network [20]. That scheme works well in 
increasing ISP'profit in wired single link QoS [21, 22] network. In fact, the real network is not only applicable for single link [23]. It is a necessity to extend the research to also include the multi-link network $[24,25]$. Link must be connected to end-user [26] and show us how many users [27] utilizing the network. It also a necessity to include charging network when users would like to switch from $3 \mathrm{G}$ to $4 \mathrm{G}$ network [7, 28, 29].

That is why in this paper, the improved IRC $[30,31]$ model by determining the base cost as a decision variable by using the BER QoS attribute is attempted to be designed. This QoS attribute pays important role in measuring the quality of network in terms of bit error per unit time. This modification model is then compared by setting the base cost and quality premium as parameters or variables. Base cost and quality premium were to be varied or be fixed to achieve some certain aim proposed by ISP to obtain better profit and make it easier for users to choose services that suit their needs.

\section{RESEARCH METHOD}

The data used in this study was obtained from one of the local server. Data then is described into grouped based on capacity usage. Data is useful in proving that improved models proposed will work perfectly in this framework. Next step is to classify the parameter and decision variables that are used in the model for the consumption of BER on the network. Determination of parameter and decision variables are based on previous original model set up by Puspita et.al [20], base cost and quality premium in network proposed by Sain [9] and BER QoS attribute in wireless network proposed by Wallenius [7, 29]. Four models with whether to vary or to fix the base price and quality premium are conducted to seek for ideal goal for ISP in achieving the best profit. The models then are run by LINGO 13.0 application software.

The idea of improved IRC basically are depicted in the Figure 1. Models from reverse charging model and knowledge of utility function to measure user's satisfaction will be included in the improved IRC. Solution by optimization tool, LINGO 13.0 as one of the powerful tool to solve the problem using branch and bound solver.

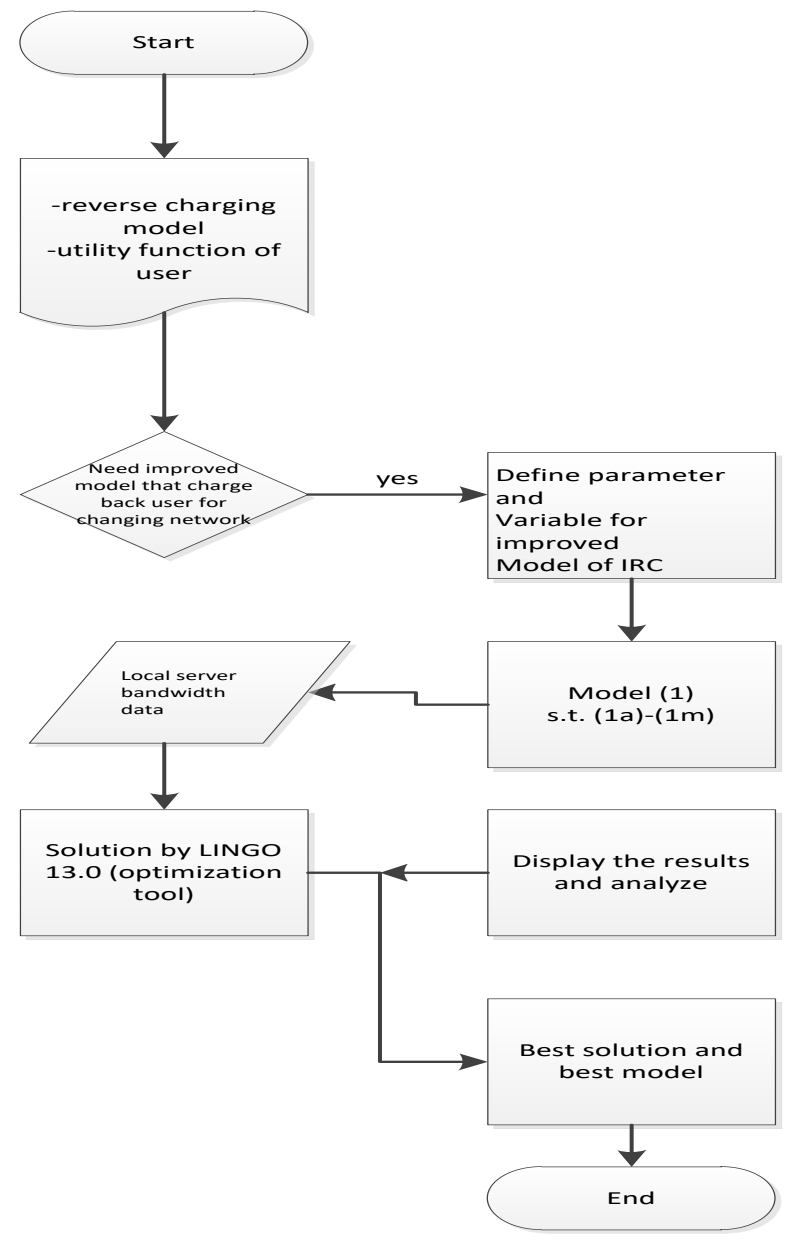

Figure 1. Flowchart of New Designed Model of Improved IRC 


\section{RESULTS AND ANALYSIS}

The improved IRC are modelled by utilizing the model proposed by Puspita et al [20, 32], Wallenius [7, 29] and Sain [9, 33]. All parameters and variables considered are models in looking into the best profit that ISPs can be achieved. Then, the general form of the model is presented as follows.

$$
\operatorname{Max} R=\sum_{i=1}^{2}\left(\left(P R_{i 1} \pm P Q_{i 1}\right)+\left(\alpha+\beta I_{i}\right) p_{i 1} x_{i 1}\right)
$$

subject to:

$$
\begin{aligned}
& \mathrm{I}_{\mathrm{i}} \mathrm{d}_{\mathrm{ik}} \mathrm{X}_{\mathrm{ik}} \leq \mathrm{a}_{\mathrm{i}} \mathrm{C} \\
& \sum_{\mathrm{i}=1}^{2} \sum_{\mathrm{k}=1}^{1} \mathrm{I}_{\mathrm{i}} \mathrm{d}_{\mathrm{ik}} \mathrm{x}_{\mathrm{ik}} \leq \mathrm{a}_{\mathrm{i}} \mathrm{C} \\
& \mathrm{a}_{\mathrm{i}} \leq 1 \leq 1, \mathrm{a}_{\mathrm{i}} \in\{0,1\} \\
& \mathrm{mi} \leq \mathrm{I}_{\mathrm{i}} \leq 1 \\
& 0 \leq \mathrm{x}_{\mathrm{ik}} \leq \mathrm{n}_{\mathrm{i}}, \mathrm{x}_{\mathrm{ik}} \geq 0 \\
& \mathrm{PQ} \mathrm{ik}_{\mathrm{ik}}=\left(1 \pm \frac{\mathrm{x}}{\mathrm{Q}_{\mathrm{bik}}}\right) \mathrm{PB}_{\mathrm{ik}} \mathrm{Lx} \\
& \mathrm{PB} \mathrm{ik}_{\mathrm{ik}}=\mathrm{a}_{\mathrm{ik}}\left(\mathrm{e}-\mathrm{e}^{-\mathrm{xB}}\right) \mathrm{T}_{\mathrm{l}} / 100 \\
& \mathrm{Lx}=\mathrm{a}\left(\mathrm{e}-\mathrm{e}^{-\mathrm{xB}}\right) \\
& \mathrm{f} \leq \mathrm{a}_{\mathrm{ik}} \leq \mathrm{g} \\
& \mathrm{h} \leq \mathrm{T}_{1} \leq \mathrm{k} \\
& 0 \leq \mathrm{x} \leq 1 \\
& 0.8 \leq \mathrm{B} \leq 1.07 \\
& \mathrm{a}=1
\end{aligned}
$$

Then, the parameter and decision variables, for instance for case 1 is defined in Table 1 and Table 2, respectively. For case $2-4$, the parameters and variables defined are almost similar. The difference is in the existence of $\alpha$ and $\beta$ as parameter or as variable.

Table 1. Parameters for Each Case on Improved IRC For Case 1

\begin{tabular}{cc}
\hline Parameter & Case $1: \alpha$ and $\beta$ as parameters \\
\hline$\alpha$ & The base price each service \\
$C$ & Premium quality for each service \\
$P R_{i k}$ & The total capacity contained in the link \\
$p_{i k}$ & The price of the service $i$ at the link $k$ \\
$m_{i}$ & Minimum QoS for Serice $i$ \\
$n_{i}$ & The number of users of the service $i$ \\
$d_{i k}$ & The capacity required to service $i$ at the link $\mathrm{k}$ \\
$f_{i}$ & Limit values specified for the service provider \\
& $\quad a_{i k}$ \\
$h$ & Limitation of traffic load this is allowed to $T_{l}$ \\
$k$ & Limitation of traffic load this is allowed to $T_{l}$ \\
$g_{i}$ & Limit values specified for the service provider \\
& $a_{i k}$ \\
\hline
\end{tabular}

Table 2. Variables for Each Case on Improved IRC Model

\begin{tabular}{cl}
\hline Variables & Case 1: $\alpha$ dan $\beta$ as parameters \\
\hline$P Q_{i k}$ & Cost change along with QoS change \\
$x_{i k}$ & The number of users of the service $i$ at link $k$ \\
$P B_{i k}$ & The basic fee for the connection with the service \\
$a_{i k}$ & Lind link $k$ \\
$I_{i}$ & The base price of the minimum required for the \\
$T_{l}$ & service $i$ \\
$L x$ & Traffic load \\
$x$ & Linearity factor \\
$B$ & Some of the increase of decrease in the value of \\
& QoS \\
& Parameter Linear set
\end{tabular}


Table 3 describes the values of parameters predetermined for the model. The values is based on the real network occur in one of local server. The value of these parameters is used to do computation on models as mathematical programming problem. Then, the model of Improved IRC when varying the cost change and value in QoS to be increased or decreased, then the following model is shown and based on whether the base cost and quality premium are parameter or variables.

Table 3. Values of Parameters in Improved IRC Model

\begin{tabular}{cc}
\hline Parameters & Value \\
\hline The cost of connecting users 1 class 1 & 0.5 \\
The cost of connecting users 2 class 1 & 0.6 \\
The base price of each service & 0.1 \\
The premium quality of each service & 0.5 \\
The total capacity contained in the class $(C)$ & 350000 \\
Minimum QoS for service 1 $\left(m_{1}\right)$ & 0.01 \\
Minimum QoS for service 2( $\left.m_{2}\right)$ & 0.01 \\
Number of users of the service 1 $\left(n_{1}\right)$ & 10 \\
Number of users of the service $2\left(n_{2}\right)$ & 10 \\
\hline
\end{tabular}

\subsection{Case 1: $\alpha$ and $\beta$ as Parameters}

Case a: $P Q_{i k}$ and $x$ increases

$$
\begin{aligned}
& \operatorname{Max} R=\left(0.5+\mathrm{PQ}_{11}\right)+\left(\left(0.1+0.5 \mathrm{I}_{1}\right) 15 \mathrm{x}_{11}\right)+\left(0.6+\mathrm{PQ}_{21}\right)+\left(\left(0.1+0.5 \mathrm{I}_{2}\right) 15 \mathrm{x}_{21}\right)+ \\
& \left(0.7+\mathrm{PQ}_{12}\right)+\left(\left(0.1+0.5 \mathrm{I}_{1}\right) 15 \mathrm{x}_{12}\right)+\left(0.8+\mathrm{PQ}_{22}\right)+\left(\left(0.1+0.5 \mathrm{I}_{2}\right) 15 \mathrm{x}_{22}\right) \\
& \text { By constraint (1a) then } \mathrm{I}_{1} 675.4053 \mathrm{x}_{11} \leq \mathrm{a}_{1} \mathrm{C}, \mathrm{I}_{2} 675.4053 \mathrm{x}_{21} \leq \mathrm{a}_{2} \mathrm{C} \\
& \text { By constraint }(1 \mathrm{~b}) \text { then }\left(\mathrm{I}_{1} 675.4053 \mathrm{x}_{11}\right)+\left(\mathrm{I}_{2} 675.4053 \mathrm{x}_{21}\right) \leq\left(\mathrm{a}_{1}+\mathrm{a}_{2}\right) \mathrm{C} \\
& \text { By (1c) then } a_{1}+a_{2}=1 \\
& \text { By (1d) then } 0.01 \leq \mathrm{I}_{1} \leq 1,0.01 \leq \mathrm{I}_{2} \leq 1 \\
& \text { By (1e) } 0 \leq \mathrm{x}_{11} \leq 10,0 \leq \mathrm{x}_{21} \leq 10 \\
& \text { By (1f,) } \mathrm{PQ}_{11}=\left(1+\frac{\mathrm{x}}{10^{-6}}\right) \mathrm{PB}_{11} \mathrm{Lx}, \mathrm{PQ}_{21}=\left(1+\frac{\mathrm{x}}{10^{-6}}\right) \mathrm{PB}_{21} \mathrm{Lx} \\
& \text { By }(1 g) P B_{11}=a_{11}\left(e-e^{-x B}\right) \frac{T_{1}}{100}, P B_{21}=a_{21}\left(e-e^{-x B}\right) \frac{T_{1}}{100} \\
& \text { By }(1 h) \text { then } L x=a\left(e-e^{-x B}\right) \\
& \text { By (1i) then } 0.05 \leq \mathrm{a}_{11} \leq 0.15,0.06 \leq \mathrm{a}_{21} \leq 0.14 \\
& \text { By (1j) then } 50 \leq \mathrm{T}_{1} \leq 1000 \\
& \text { By }(1 \mathrm{k}) \text { then } 0 \leq \mathrm{x} \leq 1 \\
& \text { By (1h) then } 0.8 \leq \mathrm{B} \leq 1.07 \\
& \text { By }(1 \mathrm{~m}) \text { then } \mathrm{a}=1
\end{aligned}
$$

For three other cases, the formulation of (2)-(2m) is exactly the same equations except for increase means having positive sign and decrease means negative sign. Then next table shows us the optimal solution for four cases of base cost and quality premium when in each of four those cases, another subcases were split and declared. 


\subsection{Case 2: $\alpha$ as Parameter and $\beta$ as Variable}

$\operatorname{Max} R=\left(0.5+P_{11}\right)+\left(\left(0.1+\beta_{1} I_{1}\right) 15 x_{11}\right)+\left(0.6+P Q_{21}\right)+\left(\left(0.1+\beta_{2} I_{2}\right) 15 x_{21}\right)+$ $\left(0.7+\mathrm{PQ}_{12}\right)+\left(\left(0.1+\beta_{1} \mathrm{I}_{1}\right) 15 \mathrm{x}_{12}\right)+\left(0.8+\mathrm{PQ}_{22}\right)+\left(\left(0.1+\beta_{2} \mathrm{I}_{2}\right) 15 \mathrm{x}_{22}\right)$

Subject to (2a)-(2m) and,

$$
\begin{aligned}
& \beta_{2} 0.01 \geq \beta_{1} 0.01 \\
& 0.01 \leq \beta_{1} \leq 0.5 \\
& 0.01 \leq \beta_{2} \leq 0.5
\end{aligned}
$$

In $(2 n)-(2 p)$ states that when $\alpha$ is as parameter and $\beta$ is as variable, then those constraints should be added to model in order to get the desired value for ISP.

\subsection{Case 3: $\alpha$ as Variable and $\beta$ as Parameter}

Max $\quad \mathrm{R}=\left(0.5+\mathrm{PQ}_{11}\right)+\left(\left(\alpha_{1}+\beta_{1} \mathrm{I}_{1}\right) 15 \mathrm{x}_{11}\right)+\left(0.6+\mathrm{PQ}_{21}\right)+\left(\left(\alpha_{2}+\beta_{2} \mathrm{I}_{2}\right) 15 \mathrm{x}_{21}\right)+$ $\left(0.7+\mathrm{PQ}_{12}\right)+\left(\left(\alpha_{1}+\beta_{1} \mathrm{I}_{1}\right) 15 \mathrm{x}_{12}\right)+\left(0.8+\mathrm{PQ}_{22}\right)+\left(\left(\alpha_{1}+\beta_{1} \mathrm{I}_{1}\right) 15 \mathrm{x}_{22}\right)$

Subject to $(2 \mathrm{a})-(2 \mathrm{~m})$ and,

$$
\begin{aligned}
& 0 \leq \alpha_{1} \leq 1 \\
& 0 \leq \alpha_{2} \leq 1 \\
& \alpha_{2}+I_{2} \geq \alpha_{1}+I_{1}
\end{aligned}
$$

in (2q)-(2s) states that when $\alpha$ is as variable and $\beta$ is as parameter, then those constraints should be added to model in order to get the desired value for ISP.

\subsection{Case 4: $\alpha$ and $\beta$ Variable}

$$
\begin{aligned}
& \operatorname{Max} R=\left(0.5+\mathrm{PQ}_{11}\right)+\left(\left(\alpha_{1}+0.5 \mathrm{I}_{1}\right) 15 \mathrm{x}_{11}\right)+\left(0.6+\mathrm{PQ}_{21}\right)+\left(\left(\alpha_{2}+0.5 \mathrm{I}_{2}\right) 15 \mathrm{x}_{21}\right)+ \\
&\left(0.7+\mathrm{PQ}_{12}\right)+\left(\left(\alpha_{1}+0.5 \mathrm{I}_{1}\right) 15 \mathrm{x}_{12}\right)+\left(0.8+\mathrm{PQ}_{22}\right)+\left(\left(\alpha_{2}+0.5 \mathrm{I}_{2}\right) 15 \mathrm{x}_{22}\right)
\end{aligned}
$$

Subject to (2a)-(2m) and,

$$
\begin{aligned}
& \alpha_{2}+\beta_{2} \mathrm{I}_{2} \geq \alpha_{1}+\beta_{1} \mathrm{I}_{1} \\
& 0 \leq \alpha_{1} \leq 1 \\
& 0 \leq \alpha_{2} \leq 1
\end{aligned}
$$

In addition, (2t)- $(2 v)$ explain that when $\alpha$ and $\beta$ are variables, and then those constraints should be added to model in order to get the desired value for ISP.

\subsection{Numerical solution}

LINGO 13.0 then be utilized to solved four cases in Tables 4-8. The model obtained is in form of mixed integer nonlinear programming, with information on value of objective function and decision variables. Table 4 depicts the variable values obtained when setting base cost and quality premium as parameter. This means that the goal of ISP is to recover cost in order to avoid bankruptcy and user can select the class according the user' preferences and budget where the model chosen is when cost change and increase in QoS value occurred. In Table 5, when setting up base price as parameter and quality premium as variable then the solution again occurs when cost change and increase in QoS value. MINLP stands for one class model, which is mixed integer nonlinear programming model.

In Tables 6 and 7, the same results occurs as in Tables 5-6. $\mathrm{PQ}_{\mathrm{ik}}$ and $\mathrm{x}$ increase shows the best solution compared to other models. In addition, the value for cost change and increase in QoS value case show the same values. It means that whether varying or fixing the base price or quality premium, then cost 
change and increase in QoS value will always occurred. Again, it tells us ISP can adopt any scheme explained, as cost change and increase in QoS value always occurred too.

Compared to previous model on improved reverse charging model proposed by Puspita et al. [20], the new model involves the cost changes and QoS changes explained in (1f)-(1g) which does not exist in previous model. The absence of those equations lead to lower objective function values obtained in every case of base cost and quality premium. The results shown in Tables 4-7 clearly show that all results yield the same values that occurs when choosing $P_{\mathrm{ij}}$ and $\mathrm{x}$ as increase parameters. It means that ISP can reach maximum profit by increasing the cost change along QoS change and the increase on QoS value. The decision to fix base price or to vary the base price to recover cost or to have market competition will always be good choices since the computation show the same values. Again, the decision to fix or to vary the quality premium as to have user selection on class and to enable ISP to promote certain class will always make an advantage for ISP since the numerical example show that the value is also the same.

Table 4. Optimal Solution of Improved IRC Using Sisfo Traffic where $\alpha$ and $\beta$ as Parameter

\begin{tabular}{ccccc}
\hline Variable & $P Q_{i k}$ and $x$ increase & $P Q_{i k}$ increase $x$ decrease & $P Q_{i k}$ decrease $x$ increase & $P Q_{i k}$ and $x$ decrease \\
\hline Model Class & MINLP & MINLP & MINLP & MINLP \\
Objective & $1.63617 \mathrm{e}+007$ & 99.6622 & 90.9376 & 91.1 \\
$P Q_{11}$ & 8462893 & 4.428739 & 0.07381231 & 0.0 \\
$P Q_{21}$ & 7898701 & 4.133489 & 0.08857477 & 0.0 \\
$x_{11}$ & 10 & 10 & 10 & 10 \\
$x_{21}$ & 0 & 0 & 0 & 0 \\
$a_{11}$ & 0.15 & 0.15 & 0.05 & 0.05 \\
$a_{21}$ & 0.14 & 0.14 & 0.06 & 0.1 \\
$I_{1}$ & 1 & 1 & 1 & 1 \\
$I_{2}$ & 0.505 & 0.505 & 0.505 & 0.505 \\
$B$ & 1.07 & 0.935 & 0.935 & 0.935 \\
$T_{l}$ & 1000 & 1000 & 50 & 50 \\
$L x$ & 2.375273 & 1.718282 & 1.718282 & 1.718282 \\
$x$ & 1 & 0 & 0 & 0 \\
\hline
\end{tabular}

Table 5. Optimal Solution of Improved IRC where $\alpha$ as Parameter and $\beta$ as Variable

\begin{tabular}{ccccc}
\hline Variable & $P Q_{i k}$ and $x$ increase & $P Q_{i k}$ increase $x$ decrease & $P Q_{i k}$ decrease $x$ increase & $P Q_{i k}$ and $x$ decrease \\
\hline Model Class & MINLP & MINLP & MINLP & MINLP \\
Objective & $1.63616 \mathrm{e}+007$ & 25.4122 & 16.6876 & 16.85 \\
$P Q_{11}$ & 8462893 & 4.428739 & 0.07381231 & 0.0 \\
$P Q_{21}$ & 7898701 & 4.133489 & 0.08857477 & 0.0 \\
$x_{11}$ & 5 & 10 & 10 & 10 \\
$x_{21}$ & 0 & 0 & 0 & 0 \\
$a_{11}$ & 0.15 & 0.15 & 0.05 & 0.05 \\
$a_{21}$ & 0.14 & 0.14 & 0.06 & 0.1 \\
$I_{1}$ & 0.01 & 0.01 & 0.01 & 0.01 \\
$I_{2}$ & 0.01 & 0.01 & 0.01 & 0.01 \\
$B$ & 1.07 & 0.935 & 0.935 & 0.935 \\
$T_{l}$ & 1000 & 1000 & 50 & 50 \\
$L x$ & 2.375273 & 1.718282 & 1.718282 & 1.718283 \\
$x$ & 1 & 0 & 0 & 0.000001 \\
\hline
\end{tabular}

Table 6. Optimal Solution of Improved IRC where $\alpha$ and $\beta$ Variables

\begin{tabular}{ccccc}
\hline Variable & $P Q_{i k}$ and $x$ increase & $P Q_{i k}$ increase $x$ decrease & $P Q_{i k}$ decrease $x$ increase & $P Q_{i k}$ and $x$ decrease \\
\hline Model Class & MINLP & MINLP & MINLP & MINLP \\
Objective & $1.63617 \mathrm{e}+007$ & 160.412 & 0.07381231 & 151.85 \\
$P Q_{11}$ & 8462893 & 4.428739 & 0.08857477 & 0.0 \\
$P Q_{21}$ & 7898701 & 4.133489 & 10 & 0.0 \\
$x_{11}$ & 10 & 10 & 0 & 0 \\
$x_{21}$ & 0 & 0 & 0.05 & 10 \\
$a_{11}$ & 0.15 & 0.15 & 0.06 & 0.05 \\
$a_{21}$ & 0.14 & 0.14 & 0.01 & 0.1 \\
$I_{1}$ & 0.01 & 0.01 & 0.01 & 0.01 \\
$I_{2}$ & 0.01 & 0.01 & 0.935 & 0.01 \\
$B$ & 1.07 & 0.935 & 50 & 0.935 \\
$T_{l}$ & 1000 & 1000 & 1.718282 & 50 \\
$L x$ & 2.375273 & 1.718282 & 0 & 1.718283 \\
$x$ & 1 & 0 & & 0.000001 \\
\hline
\end{tabular}


Table 7. Optimal Solution of IRC where $\alpha$ variable dan $\beta$ as Parameter

\begin{tabular}{ccccc}
\hline Variable & $\begin{array}{c}P Q_{i k} \text { and } x \\
\text { increase }\end{array}$ & $\begin{array}{c}P Q_{i k} \text { increase } \\
x \text { decrease }\end{array}$ & $\begin{array}{c}P Q_{i k} \text { decrease } x \\
\text { increase }\end{array}$ & $\begin{array}{c}P Q_{i k} \text { and } x \\
\text { decrease }\end{array}$ \\
\hline Model Class & MINLP & MINLP & MINLP & MINLP \\
Objective & $1.636173+007$ & 160.412 & 151.688 & 151.85 \\
$P Q_{11}$ & 8462893 & 4.428739 & 0.07381231 & 0.0 \\
$P Q_{21}$ & 7898701 & 4.133489 & 0.08857477 & 0.0 \\
$x_{11}$ & 10 & 10 & 10 & 0 \\
$x_{21}$ & 0 & 0 & 0 & 10 \\
$a_{11}$ & 0.15 & 0.15 & 0.05 & 0.05 \\
$a_{21}$ & 0.14 & 0.14 & 0.06 & 0.1 \\
$I_{1}$ & 0.01 & 0.01 & 0.01 & 0.01 \\
$I_{2}$ & 0.01 & 0.01 & 0.01 & 0.01 \\
$B$ & 1.07 & 0.935 & 0.935 & 0.935 \\
$T_{l}$ & 1000 & 1000 & 50 & 50 \\
$L x$ & 2.375273 & 1.718282 & 1.718282 & 1.718283 \\
$x$ & 1 & 0 & 0 & 0.000001 \\
\hline
\end{tabular}

\section{CONCLUSION}

The results show that the decision for ISP to adopt the model is based on ISP goals in achieving the target. Our Improved IRC, clearly shown better result since involving more parameter and variables rather than the original proposed before which only deal with single link $\mathrm{PQ}_{\mathrm{ij}}$ and $\mathrm{x}$ as increase parameters will maximize ISP goals to get higher revenue and it occurs in all cases for setting base cost and quality premium. The research seem to be quite real in some sense, but in fact, the research is in theoretical point of view. It needs more real situation though the research attempts to have multilink rather than single link. It is due to software limitation of defined parameters and variables. Therefore, for future work, the possibility to include more links is critical to allow as many as parameters and variables can be included.

\section{ACKNOWLEDGEMENTS} Year 2019.

The research is supported by Sriwijaya University through Unggulan Kompetitif Grant Scheme,

\section{REFERENCES}

[1] K. Petrova, "ISPs-pricing Internet access," Beyond Boundaries. Proceedings of the 2003 GBATA International Conference. Budapest, Hungary, pp. 1042-1051, 2003.

[2] S. Wu and R. D. Banker, "Best Pricing Strategy for Information Services," J. Assoc. Inf. Syst., vol. 11, no. 6, pp. 339-366, 2010.

[3] D. Barth, K. Deschinkel, M. Diallo, and L. Echabbi, "Pricing, QoS and Utility models for the Internet," 2004.

[4] C. Bouras and A. Sevasti, "SLA-based QoS pricing in DiffServ networks," Comput. Commun., vol. 27, pp. 18681880, 2004, doi:10.17705/1jais.00229.

[5] R. Sitepu, F. M. Puspita, E. Kurniadi, and Yunita, "Mixed Integer Nonlinear Programming (MINLP)-Based Bandwidth Utility Function On Internet Pricing Scheme With Monitoring And Marginal Cost," Int. J. Electr. Comput. Eng. (IJECE), vol. 9, no. 2, pp. 1240-1248, 2019, doi:10.11591/ijece.v9i2.pp1240-1248.

[6] R. Sitepu, F. M. Puspita, A. N. Pratiwi, and I. P. Novyasti, "Utility function-based pricing strategies in maximizing the information service provider's revenue with marginal and monitoring costs," Int. J. Electr. Comput. Eng., vol. 7, no. 2, 2017, doi:10.11591/ijece.v7i2.pp877-887.

[7] E. Wallenius and T. Hämäläinen, "Pricing Model for 3G/4G Networks," The 13th IEEE International Symposium on Personal, Indoor, and Mobile Radio Communications. Lisbon, Portugal, 2002, doi:10.1109/PIMRC.2002.1046686.

[8] R. Maiti, "A Simplified Pricing Model for the 3G/4G Mobile Networks," in Global Trends in Computing and Communication Systems, no. 269, Springer Berlin Heidelberg, pp. 535-544, 2012, doi:10.1007/978-3-642-292194_60.

[9] S. Sain, "Profit Maximisation in Multi Service Networks-An Optimisation Model," in Proceedings of the 11th European Conference on Information Systems ECIS 2003, 2003.

[10] S. Soursos, C. Courcoubetis, and R. Weber, "Dynamic bandwidth pricing: provision cots, market size, effective bandwidths and price games," J. Univers. Comput. Sci., vol. 14, no. 5, pp. 766-785, 2008.

[11] A. Amelio, "Charging Models in the Open Broadband Access Market-Theory and Practice," Telektronik 3/4.2006, 2006.

[12] R. A. M. Sprenkels, R. Parhonyi, A. Pras, B. J. van Beijnum, and B. L. de Goede, "Reverse Charging in the Internet an Architecture for a new Accounting Scheme for Internet Traffic," IEEE Workshop on IP-Oriented Operations\&Management (IPOM2000) Cracow. Cracow, 2000. 
[13] X. Ge, Y. Zhang, Y. Qian, and H. Yuan, "Effects of product characteristics on the bundling strategy implemented by recommendation systems," 2017 International Conference on Service Systems and Service Management, IEEE. Dalian, China, 2017.

[14] S. Studli, W. Griggs, E. Crisostomi, and R. Shorten, "On Optimality Criteria for Reverse Charging of Electric Vehicles," IEEE Trans. Intell. Transp. Syst., vol. 15, no. 1, pp. 451-456, 2014, doi:10.1109/ICSSSM.2017.7996297.

[15] F. Surdu, B. K. Agoston, and C. S. Martis, "Study on the behavior of a vehicle charging system with Reverse clawpole generator," 13th International Conference on Optimization of Electrical and Electronic Equipment (OPTIM), IEEE. IEEE, Brasov, Romania, 2012, doi:10.1109/OPTIM.2012.6231801.

[16] W. Fang, Q. Zhang, M. Liu, Q. Liu, and P. Xia, "Earning Maximization with Quality of Charging Service Guarantee for IoT Devices," IEEE Internet Things J., vol. 6, no. 1, pp. 1114-1124, 2019, doi:10.1109/JIOT.2018.2868226.

[17] J. Lee and G.-L. Park, "Design of a Monitoring-combined Siting Scheme for Electric Vehicle Chargers," Int. J. Electr. Comput. Eng., vol. 8, no. 6, pp. 5303-5310, 2018, doi:10.11591/ijece.v8i6.pp5303-5310.

[18] J. Lee and G.-L. Park, "Price effect analysis and pre-reseravtion scheme on electric vehicle charging networks," Int. J. Electr. Comput. Eng., vol. 9, no. 6, pp. 5586-5595, 2019, doi:10.11591/ijece.v9i6.pp5586-5595.

[19] H. Chen, Z. Su, Y. Hui, and H. Hui, "Dynamic Charging Optimization for Mobile Charging Stations in Internet of Things," IEEE Access, vol. 6, pp. 53509-53520, 2018, doi:10.1109/ACCESS.2018.2868937.

[20] F. M. Puspita, D. R. Nur, A. L. Tanjung, J. Silaen, and W. Herlina, "Mathematical model of improved reverse charging of wireless internet pricing scheme in servicing multiple QoS," J. Eng. Sci. Res., vol. 1, no. 2, pp. 89-93, 2019, doi:10.23960/jesr.v1i2.30.

[21] M. Kolhar, M. M. Abualhaj, and F. Rizwan, "QoS Design Consideration for Enterprise and Provider's Network at Ingress and Egress Router for VoIP Protocols," Int. J. Electr. Comput. Eng., vol. 6, no. 1, pp. 235-241, 2016, doi:10.11591/ijece.v6i1.pp235-241.

[22] K. Panimozhi and G. Mahadevan, "QoS Framework for a Multi-stack based Heterogeneous Wireless Sensor Network," Int. J. Electr. Comput. Eng., vol. 7, no. 5, pp. 2713-2720, 2017, doi:10.11591/ijece.v7i5.pp2713-2720.

[23] F. M. Puspita, K. Seman, B. M. Taib, and Z. Shafii, "Improved models of internet charging scheme of single bottleneck link in multi QoS networks," J. Appl. Sci., vol. 13, no. 4, 2013, doi: 10.3923/jas.2013.572.579, doi:10.3923/jas.2013.572.579.

[24] R. Odarchenko, R. Aguiar, B. Altman, and Y. Sulema, "Multilink Approach for the Content Delivery in 5G Networks," 2018 International Scientific-Practical Conference Problems of Infocommunications. Science and Technology (PIC S\&T), IEEE, 2018, doi:10.1109/INFOCOMMST.2018.8631901.

[25] P. Kántor, "Adaptive video transmission over multilink networks," in Electronics in Marine (ELMAR), International Symposium, IEEE, 2010.

[26] R. Reichl et al., "Towards a comprehensive framework for QOE and user behavior modelling," IEEE 2015 Seventh International Workshop on Quality of Multimedia Experience (QoMEX). Pylos-Nestoras, Greece, 2015, doi:10.1109/QoMEX.2015.7148138.

[27] J. Shaler Stidham, "Pricing and congestion management in a network with heterogeneous users," IEEE Trans. Automat. Contr., vol. 49, no. 6, pp. 976-981, 2004, doi:10.1109/TAC.2004.829623.

[28] O. O. Fagbohun, "Comparative studies on 3G,4G and 5G wireless technology," IOSR J. Electron. Commun. Eng., vol. 9, no. 3, pp. 88-94, 2014, DOI: 10.9790/2834-0925133139.

[29] E. R. Wallenius, "Control and Management of Multi-Access Wireless Network," University of Jyvaskyla, Jyvaskyla, 2005.

[30] P. Loiseau, G. Schwartz, J. Musacchio, and S. Amin, "Incentive schemes for Internet congestion management: Raffles versus time-of-day pricing," in IEEE-2011 49th Annual Allerton Conference on Communication, Control, and Computing, 2011, doi:10.1109/Allerton.2011.6120156.

[31] K. R. Gadham and T. Ghose, "Design of incentive price for voluntary Demand Response Programs using fuzzy system," 2016 International Conference on Electrical Power and Energy Systems (ICEPES), IEEE, Bhopal, India, 2016, doi:10.1109/ICEPES.2016.7915958.

[32] F. M. Puspita, S. Anggraini, B. Arisha, W. Herlina, and Yunita, "Improved internet wireless reverse charging models under multi link service network by end-to-end delay QoS attribute," 2nd International Seminar on Research of Information Technology and Intelligent Systems 2019, IEEE. Yogyakarta, 2019, doi:10.1109/ISRITI48646.2019.9034628.

[33] S. Sain, "Pricing the Internet: The One-Component versus Two-Component Pricing Mechanism-An Evaluation," 14th Bled Electronic Commerce Conference, Bled, Slovania. Bled, Slovania, 2001. 


\section{BIOGRAPHIES OF AUTHORS}
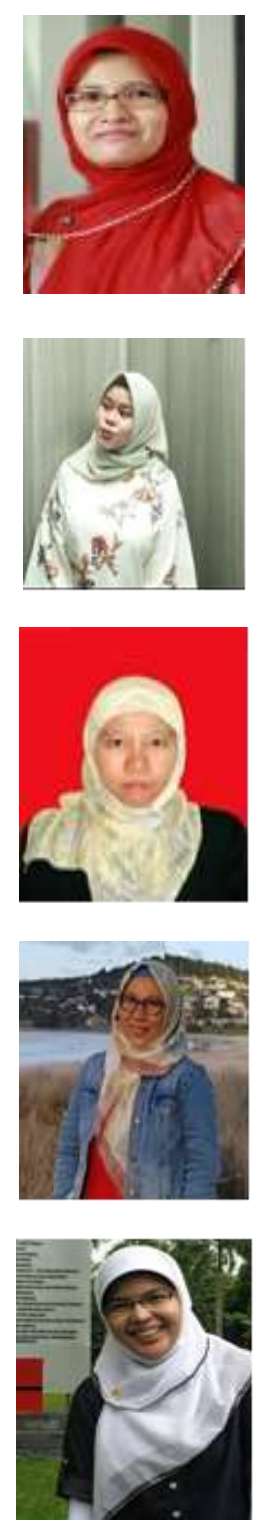

Fitri Maya Puspita received her S.Si degree in Mathematics from Sriwijaya University, South Sumatera, Indonesia in 1997. Then she received her M.Sc in Mathematics from Curtin University of Technology (CUT) Western Australia in 2004. She graduated from Faculty of Science and Technology Islamic Science University of Malaysia (USIM), Nilai, Negeri Sembilan Darul Khusus, Malaysia in 2015. She has been a Mathematics Department member at Faculty mathematics and Natural Sciences Sriwijaya University South Sumatera Indonesia since 1998. Her research interests include discrete optimization, inventory and pricing scheme in QoS network.

Rohania is a student majoring in mathematics, Faculty of Mathematics and Natural Sciences, Sriwijaya University. She received her S.Si Degree in mathematics in the early 2020. Her interest focuss on Improved Reverse Charging Models for the Multi Link Internet Pricing Scheme on the Multi-Service Network QoS bit Error Rate.

Evi Yuliza received her received her S.Si degree in Mathematics from Sriwijaya University, South Sumatera, Indonesia in 2000. Then she received M.Si in Mathematics in University of Gajah Mada, Indonesia in 2004. She is currenty in a final stage of a Ph.D Program at Sriwijaya University. Her Dissertation focuss on the robust optimization of soft time windows and hard time windows of vehicle routing problem. She has been a Mathematics Department member at Faculty mathematics and Natural Sciences Sriwijaya University South Sumatera Indonesia. Her research interest includes Algebra, Analysis and optimization and its applications.

Wenny Herlina received her S.T degree in Mining Engineering from Sriwijaya University, South Sumatera Indonesia. Then she received her M.T in Mining from Bandung Institute of Technology. She has been a Mining Department member at Faculty of Engineering Sriwijaya University South Sumatera Indonesia since 1998. Her research interests include charcoal exploration, geological map, formation evaluation, Oil and Gas production techniques and reservoir technique.

Yunita received her S.Si degree in Mathematics from Sriwijaya University, South Sumatera, Indonesia in 2006. Then she received her M.Cs in Computer Science from Gadjah Mada University. She has been a Informatics Department member at Faculty of Computer Science Sriwijaya University South Sumatera Indonesia since 2015. Her research interests include computer science especially deadling with system of decision making, informatics logic, operation system and theory of language and automata. 